\title{
Comparison of mineral trioxide aggregate and formocresol as pulp medicaments for pulpotomies in primary molars
}

- Mineral trioxide aggregate (MTA) was assessed in pulpotomised primary molars.

- The clinical and radiographic success rate of MTA was recorded at 24 months follow-up.

- This clinical trial study showed the success of white MTA in primary molars.

H. Noorollahian'

\begin{abstract}
Purpose The aim of this study was to compare the effect of white mineral trioxide aggregate (MTA) to that of formocresol (FC) as pulp dressing agents in pulpotomised primary molars. Methods In this clinical trial study, 60 lower second primary molars of 46 children were treated by a conventional pulpotomy technique. The teeth were randomly assigned to the MTA (experimental) and FC (control) groups by random numbered table. Following removal of the coronal pulp and haemostasis, the pulp stumps were covered with an MTA paste in the experimental group. In the control group, FC was placed with a cotton pellet over the pulp stumps. The teeth of both groups were restored with stainless steel crowns. Children arrived for clinical and radiographic follow-up evaluation after 6,12 and 24 months. Results The treated teeth in FC group $(n=18)$ were clinically and radiographically successful after 24 months. The radiographic follow-up evaluation revealed one failure (furcation involvement) in 18 molars treated with MTA after 24 months. The treated teeth in MTA group were clinically successful 24 months postoperatively. Pulp canal obliteration was observed in one of the teeth treated with MTA and four of the teeth treated with FC. Conclusion MTA could be used as a safe medicament for pulpotomy in cariously exposed primary molars and could be a substitute for FC.
\end{abstract}

\section{INTRODUCTION}

Recent progress in understanding the molecular and cellular changes during tooth development and how they are mimicked during tissue repair, offers the opportunity to assess the biologic validity of the various vital pulp treatments. Under this light, indirect pulp treatment can be an acceptable procedure for primary teeth with reversible pulp inflammation, provided that this diagnosis is based on a good history, a proper clinical and radiographic examination, and the tooth had been sealed with a leakage-free restoration. ${ }^{1}$ Direct pulp

\footnotetext{
Assistant Professor of Paedodontics, Department of Paedodontics, Faculty of Dentistry, Zahedan University of Medical Sciences, East Azadegan Avenue, Zahedan, Iran, P.O. BOX: 9817699638

Correspondence to: Dr Homa Noorollahian

Email:ma_azadi@yahoo.com
}

Online article number E20

Refereed Paper - accepted 11 June 2007

DOI: 10.1038/sj.bdj.2008.319

${ }^{\oplus}$ British Dental Journal 2008; 204: E20 capping of carious exposures in young permanent teeth is an accepted procedure, but in primary teeth it is contraindicated. ${ }^{2}$ In younger children, pulpotomy is indicated for any carious or traumatic pulp exposures in primary teeth. ${ }^{2}$ Formocresol (FC) has been the most popular pulp dressing material for pulpotomised primary molars for many years but, due to its deleterious effect, ${ }^{3,4}$ the use of FC is decreasing considerably worldwide. Ferric sulphate has been proposed as a substitute for $\mathrm{FC}$, and its success rates are comparable to those of FC. ${ }^{5-7}$

More recently, considerably better results have been obtained with MTA (mineral trioxide aggregate). ${ }^{8-10}$ MTA was introduced to endodontics by Torabinejad et al. in 1993. ${ }^{11}$ MTA is marketed in grey and white preparations. In recent years, the use of the white (tooth-coloured) preparation has become more popular in incisor teeth due to the discolouration using grey MTA. ${ }^{12-14}$ MTA is a powder that consists of fine hydrophilic particles that in the presence of water, or moisture, forms a colloidal gel that solidifies to form hard cement within approximately four hours. The principal components of the grey-coloured formula are tricalcium oxide, tricalcium silicate, bismuth oxide, dicalcium silicate, tricalcium aluminate, tetracalcium aluminoferrite and calcium sulfate dihydrate. ${ }^{15-18}$ The more aesthetic white-coloured preparation lacks the tetracalcium aluminoferrite. ${ }^{19,20}$ Lately, MTA has been used as a pulpotomy medicament in primary molars and it was found to be a successful material. . $^{13,21,22}$

The objective of this study was to clinically and radiographically evaluate the effects of tooth-coloured (white) MTA as a pulp dressing agent in pulpotomised lower second primary molars for 24 months and compare them to those of FC.

\section{METHODS AND MATERIALS}

The procedure and its possible discomfort and benefits were explained fully to 
the parents of the children involved and their written consent was obtained prior to the investigation. Also, the approval of the Undersecretary for Research at Zahedan University of Medical Sciences was obtained prior to the study.

Forty-six Iranian children (29 boys, 17 girls) were selected for clinical and radiographic study from patients attending the clinic of the Paediatric Dentistry Department, Faculty of Dentistry, Zahedan University of Medical Sciences. Their ages ranged between 5-7 years, with a mean age of 6.08. The children had no systemic diseases. The suitability of the teeth for pulpotomy was assessed by the author who also performed the procedures. The criteria for selection of the teeth to be included in the study were: 1) symptomless exposure of vital pulp by caries; 2) no clinical or radiographic evidence of pulp degeneration, such as excessive bleeding from the root canal, internal root resorption, interradicular and/or periapical bone destruction, swelling or sinus tract; and 3) the possibility of proper restoration of the teeth.

Sixty lower second primary molars were treated by a conventional pulpotomy technique. The teeth were randomly assigned to either the control or experimental group (30 teeth each) by random numbered table. In case a child had two molars needing pulpotomy, the second tooth was assigned to the alternative group.

All molars were treated with inferior alveolar nerve block anaesthesia and rubber dam isolation. After caries removal, coronal access was obtained with a 330 high-speed bur with water spray to expose the pulp chamber. Following removal of the coronal pulp with a round bur and haemostasis, the pulp stumps in the experimental group were covered with an MTA paste, obtained by mixing MTA powder with distilled water in a 3:1 powder/water ratio, according to the manufacturer's recommendations. The MTA used in this study was toothcoloured (white) MTA (Dentsply, Tulsa Dental). The choice of white MTA was made purely because it was the newest product. In this group a cotton pellet moistened with normal saline was placed over the MTA paste and the tooth was temporarily restored using fast-setting zinc oxide-eugenol (ZOE), because the MTA hardened within approximately four hours.

In the control group, a cotton pellet moistened with 1:5 diluted FC (Buckleys) was placed for five minutes on the pulp stumps and then the pulps were covered with zinc oxide-eugenol (ZOE) paste. In both groups, teeth were restored with stainless steel crown (in MTA group after 24 hours and in FC group immediately).

The children were recalled for clinical and radiographic examination after 6,12 and 24 months. When a patient did not respond or cancelled an appointment, further attempts were made to contact the parents and a follow-up examination was rescheduled. The children were examined clinically and radiographically at follow-up by the author who was blind to which treatment group the subject belonged. The dental assistant recorded the name, code of file, residence and telephone number of patients on a separate follow-up index card for 6,12 and 24 months.

Teeth were scored as clinical successes if they had no pain symptoms, tenderness to percussion, swelling, fistulation or pathologic mobility. Teeth were scored as radiographic successes if they showed no evidence of radicular radiolucency, internal or external root resorption, or periodontal ligament space widening. The treatment was regarded as a failure when one or more of the following signs were present: internal root resorption, furcation radiolucency, periapical bone destruction, pain, swelling, or sinus tract. Pulp canal obliteration (PCO) was not regarded as a failure.

The data were analysed to assess the success rate of the treatment at the various follow-up periods. The differences were statistically analysed using the Fisher's exact test.

\section{RESULTS}

Six months follow-up: 43 children with 56 teeth arrived for postoperative evaluation. All the treated teeth in the two groups $(\mathrm{FC}=27, \mathrm{MTA}=29$ ) were clinically and radiographically successful.

Twelve months follow-up: 41 children with 53 teeth arrived for clinical and radiographic examination. The treated teeth in the FC group ( $\mathrm{n}=24)$ were clinically

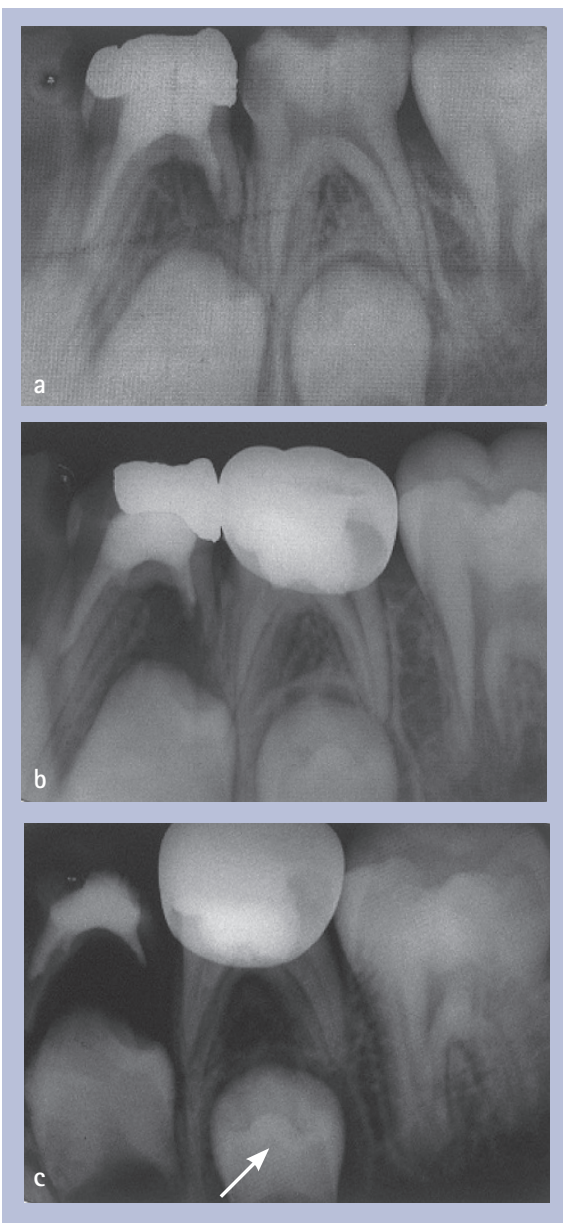

Fig. 1 Furcation MTA pulpotomy failure at 12 months: a) pre-treatment, b) 6 month evaluation, c) 12 month evaluation

and radiographically successful. The treated teeth in the MTA group $(\mathrm{n}=29)$ were clinically successful but the radiographic follow-up evaluation revealed one failure, furcation involvement, in molars treated with MTA (Fig. 1).

Twenty-four months follow-up: 27 children with 36 teeth arrived for postoperative evaluation. The treated teeth in the FC group ( $\mathrm{n}=18$ ) were clinically and radiographically successful (Fig. 2). The treated teeth in the MTA group ( $\mathrm{n}=$ 18) were clinically successful. Figure 3 shows the radiographic success in a molar treated with MTA. The radiographic follow-up evaluation revealed one failure, furcation involvement, in another of the molars treated with MTA (Fig. 4).

All the teeth were scored as clinical successes at the 6, 12 and 24-month postoperative evaluations. The radiographic assessments of the teeth are shown in Table 1.

Pulp canal obliteration was observed in one of the teeth treated with MTA and four of the teeth treated with FC. The 


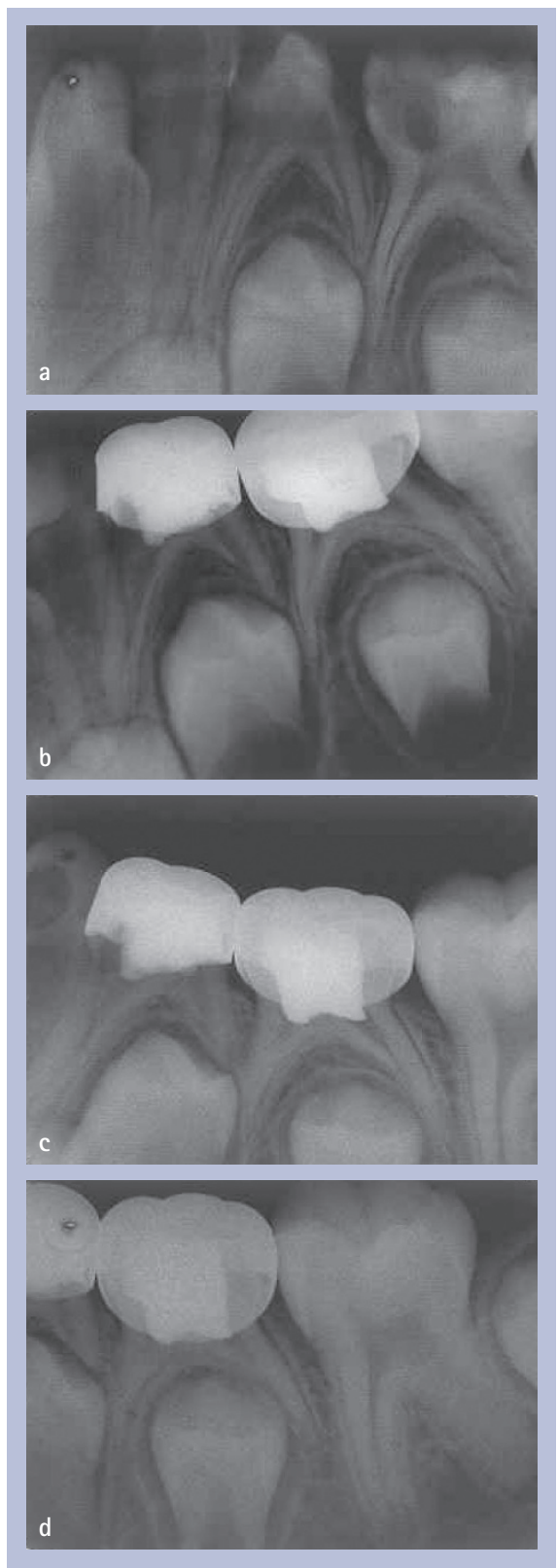

Fig. 2 Pulpotomy radiographic success in a second primary molar treated with FC: a) pre-treatment, b) 6 month evaluation, c) 12 month evaluation, d) 24 month evaluation

time of detection of obliteration was 12 months after treatment.

\section{DISCUSSION}

This study examined the clinical and radiographic success rate of pulpotomies with MTA in comparison with FC and showed the samples treated with MTA had the same success rate as those treated with FC.

The retention of pulpally involved primary teeth in a healthy state until the time of normal exfoliation remains one of the challenges for paedodontists. Concerns have been raised about the toxicity and potential carcinogenicity of the
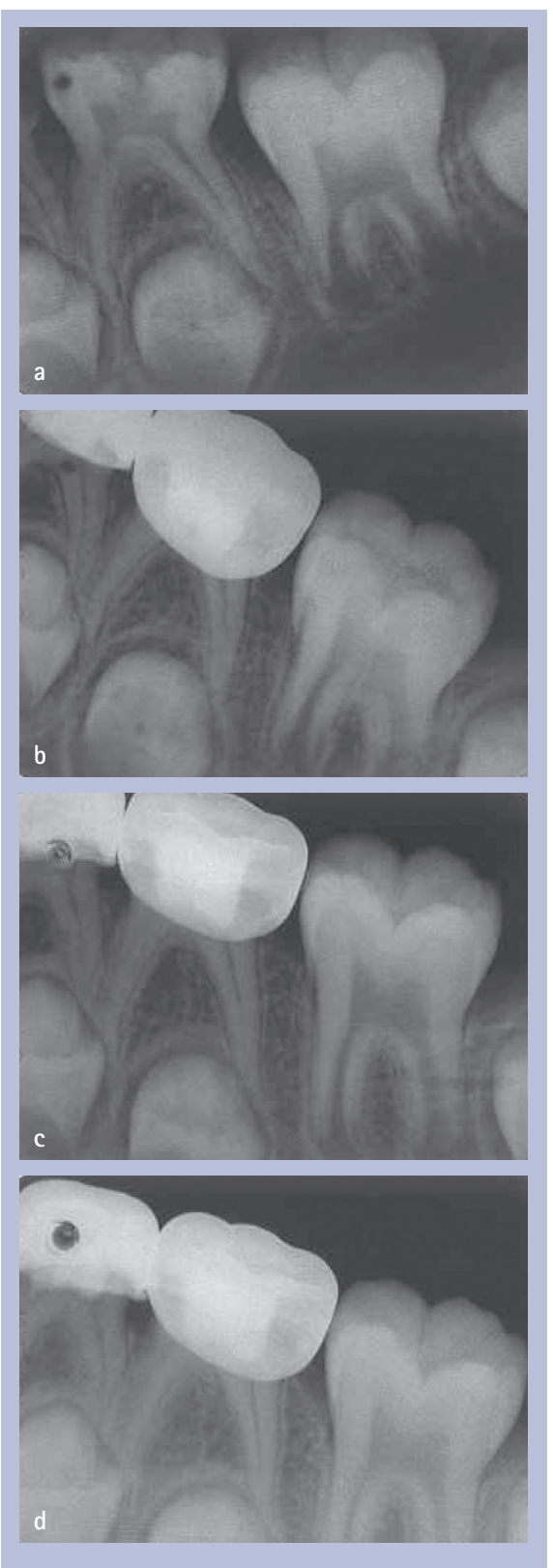

Fig. 3 Pulpotomy radiographic success in a second primary molar treated with MTA: a) pre-treatment, b) 6 month evaluation, c) 12 month evaluation, d) 24 month evaluation
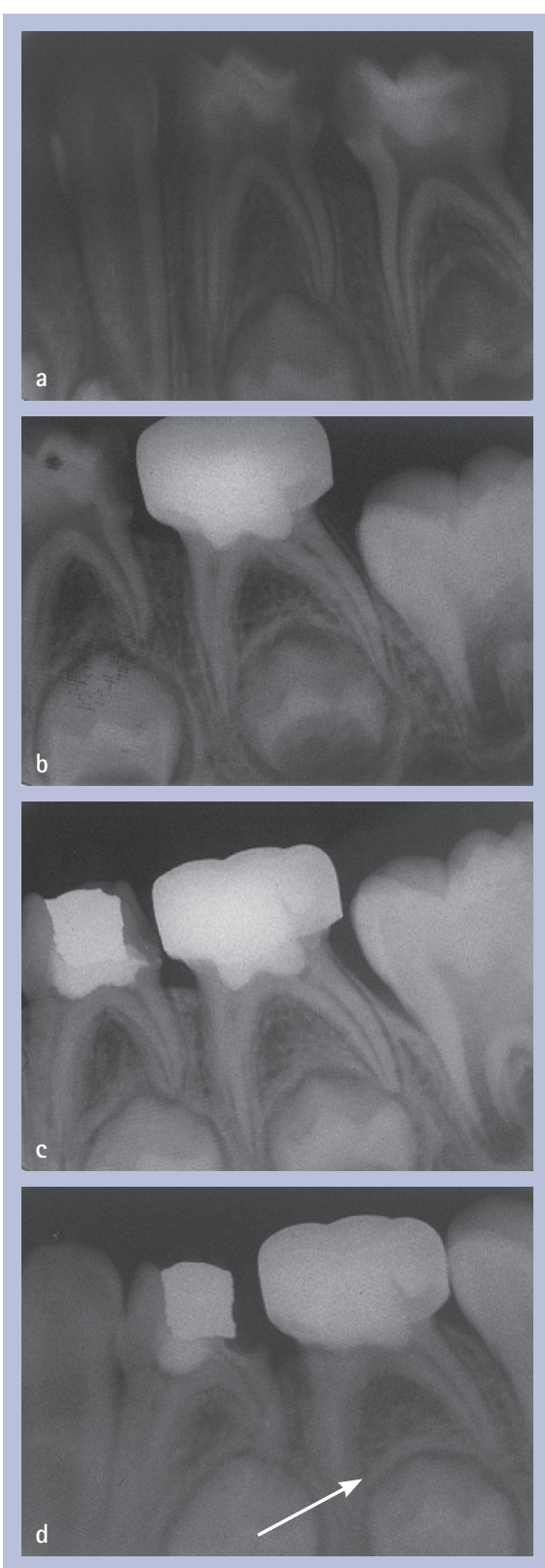

Fig. 4 Furcation MTA pulpotomy failure at 24 months: a) pre-treatment, b) 6 month evaluation, c) 12 month evaluation, d) 24 month evaluation

Table 1 Radiographic assessment of the two groups at different evaluation periods

\begin{tabular}{|c|c|c|c|c|}
\hline & & \multicolumn{3}{|c|}{ Evaluation periods } \\
\hline \multicolumn{2}{|c|}{ Material } & $\begin{array}{l}6 \text { months* } \\
\text { Number }(\%)\end{array}$ & $\begin{array}{l}12 \text { months* } \\
\text { Number }(\%)\end{array}$ & $\begin{array}{l}24 \text { months* } \\
\text { Number }(\%)\end{array}$ \\
\hline \multirow{3}{*}{ MTA } & Success & $29(100)$ & $28(96.5)$ & $17(94.4)$ \\
\hline & Failure & $0(0)$ & $1(3.5)$ & $1(5.6)$ \\
\hline & Total & $29(100)$ & $29(100)$ & $18(100)$ \\
\hline \multirow{3}{*}{$\mathrm{FC}$} & Success & 27 (100) & $24(100)$ & $18(100)$ \\
\hline & Failure & $0(0)$ & $0(0)$ & $0(0)$ \\
\hline & Total & $27(100)$ & $24(100)$ & $18(100)$ \\
\hline
\end{tabular}


popular pulpotomy medicament (FC) and alternatives have been proposed to maintain partial pulp vitality.

MTA has been proposed as a potential medicament for various pulpal procedures in permanent teeth, eg pulp capping, apexification, repair of root perforations etc, and has had successful results. ${ }^{20-24}$ With due attention to the biocompatibility and biological seal of MTA, several studies have been performed to evaluate its efficacy as a pulpotomy medicament in primary molars. ${ }^{8-10,13,21}$

Eidelman et $a l .{ }^{8}$ showed MTA pulpotomies in primary molars that were followed up for 6-30 months were clinically and radiographically successful. In the studies of Naik ${ }^{9}$ and Maroto et al., ${ }^{13}$ the clinical and radiographic evaluations were done at six months after pulpotomy in primary molars. Their studies also showed that MTA was a successful material. Agamy et al..$^{10}$ compared the success of grey MTA, white MTA and FC as pulp dressings in pulpotomised primary teeth using clinical, radiographic and histologic examinations. They concluded that grey MTA appears to be superior to white MTA and FC in pulpotomised primary teeth and confirmed that the biocompatibility of MTA was similar to that found in other in vivo and in vitro studies. ${ }^{23,26,27}$

The results of this study showed that all the treated teeth in the MTA and FC groups were clinically successful. Also, the radiographic success of the FC group was complete within the 6 to 24 months follow-up time. The radiographic evaluation revealed one failure at 12 months postoperatively and one failure at 24 months postoperatively in molars treated with white MTA. The present study did not see the failure rate in white MTA pulpotomies that Agamy et al. ${ }^{10}$ found. One reason may be that the present study treated second primary molars only, while the above-mentioned studies treated all primary molars. $\mathrm{Vij}^{28}$ found that first primary molar pulpotomies had a $61 \%$ success rate while the success rate for second molars was $83 \%$.

Farsi et al. ${ }^{21}$ reported a significant difference between the two groups (MTA and FC pulpotomies in primary molars) after 24 months of radiographic evaluation, but the results of this study were not statistically significant and agree with the study of Holan et al. ${ }^{22}$ In their study, MTA showed a higher (though not statistically significant) long-term clinical and radiographic success rate than formocresol. ${ }^{22}$

In spite of the similarity of success rates of FC and MTA in this study, one clinical disadvantage of MTA compared to FC is the fact that the tooth has to be restored after 24 hours to allow time for the MTA to set. In addition, MTA is more expensive and more difficult to prepare than FC.

In the present study there was a high drop-out rate after 24 months (12 out of 30 teeth in two groups) and it is possible that the some of failures have not returned. Therefore further studies with a larger sample size and longer follow-up periods are recommended.

Pulp canal obliteration has been reported as a common radiographic finding in pulpotomised teeth treated with FC, ${ }^{8}$ MTA $^{8,10}$ and ferric sulfate. ${ }^{29}$ In the present study pulp canal obliteration was present in the two groups. The obliteration is the result of odontoblastic activity and suggests that the tooth is retaining some degree of vitality ${ }^{30}$ and therefore was not regarded as failure.

\section{CONCLUSION}

Based on the present study, MTA could be used as a safe medicament for pulpotomy in cariously exposed primary teeth and could be a substitute for FC.

1. Fuks A B. Current concepts in vital primary pulp therapy. Eur J Paediatr Dent 2002; 3: 115-120.

2. American Academy of Pediatric Dentistry. Guideline on pulp therapy for primary and young permanent teeth. In American Academy of Pediatric Dentistry reference manual 2005-2006. Clinical guidelines. pp 130-134. Chicago: AAPD, 2005.

3. Judd P L, Kenny D J. Formocresol concern. A review. J Can Dent Assoc 1987; 53: 401-404. 4. International Agency for Research on Cancer. IARC classifies formaldehyde as carcinogenic to humans. Press release no. 153. Lyon: World Health Organization International Agency for Research on Cancer, 2004.

5. Fei A L, Udin R D, Johnson R. A clinical study of ferric sulfate as a pulpotomy agent in primary teeth. Pediatr Dent 1991; 13: 327-332.

6. Smith N L, Seale N S, Nunn M E. Ferric sulfate pulpotomy in primary molars: a retrospective study. Pediatr Dent 2000; 22: 192-199.

7. Fuks A B, Holan G, Davis J M, Eidelman E. Ferric sulfate versus diluted formocresol in pulpotomized primary molars: long-term follow up. Pediatr Dent 1997: 19: 327-330.

8. Eidelman E, Holan G, Fuks A B. Mineral trioxide aggregate vs. formocresol in pulpotomized primary molars: a preliminary report. Pediatr Dent 2001; 23: 15-18.
9. Naik S, Hegde A M. Mineral trioxide aggregate as a pulpotomy agent in primary molars: an in vivo study. J Indian Soc Pedod Prev Dent 2005; 23: 13-16.

10. Agamy H A, Bakry N S, Mounir M M, Avery D R. Comparision of mineral trioxide aggregate and formocresol as pulp-capping agents in pulpotomized primary teeth. Pediatr Dent 2004; 26: 302-309.

11. Torabinejad M, Watson T F, Pitt Ford T R. Sealing ability of a mineral trioxide aggregate when used as a root end filling material. J Endod 1993; 19: 591-595.

12. Al-Hezaimi $\mathrm{KH}, \mathrm{Al}$-Hamdan $\mathrm{KH}$, Naghsbandi J, Oglesby S, Simon J, Rotstein I. Effect of whitecolored mineral trioxide aggregate in different concentrations on Candida albicans in vitro. J Endod 2005; 31: 684-686.

13. Maroto M, Barberia E, Planells P, Garcia Godoy F. Dentin bridge formation after mineral trioxide aggregate (MTA) pulpotomies in primary teeth. Am J Dent 2005; 18: 151-154.

14. Parirokh $M$, Asgary S, Eghbal M J et al. A comparative study of white and grey mineral trioxide aggregate as pulp capping agents in dog's teeth. Dent Traumatol 2005; 21: 150-154.

15. Torabinejad M, Hong C U, Pitt Ford T R, Kettering $J$ D. Cytotoxicity of four root end filling materials. J Endod 1995; 21: 489-492

16. Torabinejad M, Rastegar A F, Kettering J D, Pitt Ford T R. Bacterial leakage of mineral trioxide aggregate as a root-end filling material. J Endod 1995; 21: 109-112.

17. Abedi $H$ R, Ingle J I. Mineral trioxide aggregate: a review of a new cement. J Calif Dent Assoc 1995; 23: 36-39.

18. Torabinejad M, Hong C U, McDonald F, Pitt Ford T R. Physical and chemical properties of a new rootend filling material. J Endod 1995; 21: 349-353.

19. Ferris D M, Baumgartner J C. Perforation repair comparing two types of mineral trioxide aggregate. J Endod 2004; 30: 422-424.

20. Stowe T J, Sedgley C M, Stowe B, Fenno J C. The effects of chlorhexidine gluconate $(0.12 \%)$ on the antimicrobial properties of tooth-colored ProRoot mineral trioxide aggregate. J Endod 2004; 30: 429-431.

21. Farsi N, Alamoudi N, Balto K, Mushayt A. Success of mineral trioxide aggregate in pulpotomized primary molars. J Clin Pediatr Dent 2005: 29: 307-311.

22. Holan G, Eidelman E, Fuks A B. Long-term evaluation of pulpotomy in primary molars using mineral trioxide aggregate or formocresol. Pediatr Dent 2005; 27: 129-136.

23. Pitt Ford T R, Torabinejad M, Abedi H R, Bakland L $\mathrm{K}$, Kariyawasam S P. Using mineral trioxide aggregate as a pulp-capping material. J Am Dent Assoc 1996; 127: 1491-1494.

24. Main C, Mirzayan N, Shabahang S, Torabinejad M. Repair of root perforations using mineral trioxide aggregate: a long-term study. J Endod 2004; 30: 80-83.

25. Hayashi M, Shimizu A, Ebisu S. MTA for obturation of mandibular central incisors with open apices: case report. J Endod 2004; 30: 120-122.

26. Yaltirik $M, O$ zbas $H$, Bilgic $B$, Issever $H$. Reactions of connective tissue to mineral trioxide aggregate and amalgam. J Endod 2004; 30: 95-99.

27. Balto H A. Attachment and morphological behavior of human periodontal ligament fibroblasts to mineral trioxide aggregate: a scanning electron microscope study. J Endod 2004; 30: 25-29.

28. Vij R, Coll J A, Shelton P, Faroog N S. Caries control and other variables associated with success of primary molar vital pulp therapy. Pediatr Dent 2004; 26: 214-220.

29. Casas M J, Kenny D J, Johnston D H, Judd P L. Long-term outcomes of primary molar ferric sulfate pulpotomy and root canal therapy. Pediatr Dent 2004; 26: 41-48.

30. Tziafas D, Pantelidou O, Alvanou A, Belibasakis $G, P a p a d i m i t r i o u ~ S$. The dentinogenic effect of mineral trioxide aggregate (MTA) in short-term capping experiments. Int Endod J 2002; 35: $245-254$ 